\title{
EVALUACIÓN DE UNA TÉCNICA BIL.AMINAR PARA CUBRIR RECESIONES GINGIVALES
}

\author{
Odontólogo, U. Santo Tomás. Especialista en Prótesis Periodontal, C.E.S. \\ Docente, Universidad de Antioquia.
}

Autor responsable de correspondencia: Dr. Carlos Martín Ardila M. Correo electrónico: carlosmartin@odontologo.com

Investigación presentada en el I Congreso Iberopanamericano de Periodoncia en Lima, Perú, octubre 2003 y en el XIX Congreso Científico Odontológico de la Asociación de Odontólogos Costarricenses en San José, Costa Rica, junio de 2004

\begin{abstract}
RESUMEN
Objetivo: El propósito de este estudio fue evaluar por un período de dos años, la reducción de recesiones gingivales mediante la Técnica Bilaminar con injertos subepiteliales de tejido conectivo bajo colgajos de espesor total posicionados coronalmente. Materiales y métodos: Veinte recesiones vestibulares (con promedio de $3.4 \mathrm{~mm}$ y rango de 3 a $4 \mathrm{~mm}$; Clase I y II de Miller) en 10 pacientes, se trataron con una técnica bilaminar mediante la combinación de un injerto subepitelial de tejido conectivo combinado con un colgajo pediculado de espesor total desplazado coronalmente. Se evaluó la cantidad de recesión gingival (RG), el nivel de inserción clínica (NIC) y la amplitud de encía queratinizada (AEQ) durante los dos (2) años posteriores a la cirugía. Las medidas se tomaron prequirúrgicamente, y cada 1, 3, 6, 12, 18 y 24 meses posquirúrgicos. La estadística descriptiva fue expresada con promedios más desviación estándar (DS). Las variaciones longitudinales fueron evaluadas por medio de análisis de varianza (RG, inserción trepadora NIC y AEQ) o test de Friedman (IP e IG).

Resultados: La RG disminuyó de $3.4 \pm 0.58 \mathrm{~mm}$ como punto de inicio a $0.31 \pm 0.43$ a los 24 meses; representa una reducción de $3.16 \mathrm{~mm}$ correspondiendo al $91.2 \%$ en promedio del cubrimiento radicular. El NIC disminuyó significativamente a los 24 meses desde $5.06 \pm 0.71$ a $2.1 \pm 0.58$. A los 24 meses, se obtuvo $3.17 \mathrm{~mm}$ de ganancia de inserción. La AEQ se incrementó significativamente después de los 24 meses (1.98). RG, NIC y AEQ tuvieron los resultados más positivos a los doce (12) meses y se mantuvieron estables hasta los veinticuatro (24) meses.

Conclusiones: La técnica bilaminar con injertos subepiteliales de tejido conectivo combinados con colgajos desplazados coronalmente de espesor total es predecible para cubrir raíces y la utilidad obtenida por esta técnica puede mantenerse bien. [Ardila CM. Evaluación de una técnica bilaminar par cubrir recesiones gingivales. Ustasalud Odontología 2004; 3: 24 - 31]
\end{abstract}

Palabras clave: Recesión gingival, Injertos, Tejido conectivo.

\section{EVALUATION OF A BILAMINAR TECHNIQUE FOR GINGIVAL RECESSION COVERAGE}

\begin{abstract}
Objective: The purpose of this study was to evaluate, over a two year period, the decrease of gingival recession by using a Bilaminar Technique with a subepithellial free connective tissue graft placed under a coronally advanced full-thickness pedicle flap.

Material and methods: Twenty buccal recessions (mean $3.4 \mathrm{~mm}$; range 3 to $4 \mathrm{~mm}$; Miller Class I, II) in 10 patients were treated, using a bilaminar technique by a combination of a subepithelial connective tissue graft placed under a coronally advanced full-thickness pedicle flap. Amount of gingival recession (GR), clinical attachments loss (CAL), and width of keratinized gingiva (WKG) were followed for 2 years after surgery. The measurements were performed at presurgery, and 1, $3,6,12,18$ and 24 months postsurgery. The descriptive statistic was expressed with averages plus standard deviation (SD). The longitudinal variations were evaluated by means of variance analysis (RG, creeping attachment, NIC and $\mathrm{AEQ}$ ) or test of Friedman (IP and IG).

Results: GR decreased from $3.4 \pm 0.58 \mathrm{~mm}$ at baseline to $0.31 \pm 0.43$ at 24 months, which means a decrease of $3.16 \mathrm{~mm}$, corresponding to $91.2 \%$ mean root coverage. CAL was significantly decreased at 24 months from $5.06 \pm 0.71$ to $2.10 \pm 0.58$. At 24 months, 3.17 of attachment gain was obtained. WKG significantly increased after 24 months (1.98). GR, CAL, and WKG had the most positive outcomes at 12 months and were maintained at stable levels throughout the 24 month observation period.

Conclusions: The bilaminar technique employing a connective tissue graft with a partial thickness coronal advancement pedicle is a predictable method for root coverage and the clinical outcomes gained by this technique can be well maintained.
\end{abstract}

Key words: Gingival recession, Grafts, Connective tissue. 


\section{INTRODUCCIÓN}

Cubrir superficies radiculares expuestas se ha convertido en una parte integral de la práctica quirúrgica periodontal. Las indicaciones para cubrir superficies radiculares incluyen estética, sensibilidad radicular, caries radicular y ausencia de encía queratinizada. ${ }^{1} \mathrm{Mu}-$ chos enfoques quirúrgicos como injertos pediculados, ${ }^{2-5}$ injertos gingivales libres, ${ }^{6-10}$ injertos de tejido conectivo ${ }^{9-24}$ y regeneración tisular guiada ${ }^{23-28}$ han mostrado resultados efectivos en el cubrimiento de recesiones gingivales. Cada una de estas técnicas tiene sus ventajas y desventajas, indicaciones y contraindicaciones. Los resultados no son uniformes.

Los injertos gingivales libres presentan una discrepancia de color con el tejido circundante; ha sido descrito como de apariencia queloide. ${ }^{12,29}$ Los injertos pediculados, incluidos los lateral o coronalmente posicionados, pueden producir un resultado más estético; sin embargo, estos procedimientos están indicados, cuando existe un adecuado donante adyacente al defecto. ${ }^{29,30}$ La regeneración tisular guiada (RTG) por membranas no reabsorbibles ${ }^{2426} 0$ bioabsorbibles, ${ }^{23,27,28}$ ha sido empleada para cubrir recesiones gingivales; sin embargo, la exposición de la membrana, ha sido asociada a la significativa reducción en los resultados de cubrimiento radicular.

La utilización de injertos de tejido conectivo combinado con un colgajo pediculado, posicionado coronalmente, ${ }^{12,15,16}$ los colgajos pediculados posicionados lateralmente, ${ }^{13} \mathrm{el}$ doble pediculado, ${ }^{13,14,19-21,23}$ el colgajo en bolsillo, ${ }^{9,11,22}$ y la técnica de tunelización ${ }^{17,18}$ han demostrado predecibilidad y cubrimiento radicular estético en varios estudios clínicos. No obstante, muchos de estos estudios carecen de seguimiento a largo plazo.

El propósito de este estudio es evaluar longitudinalmente, en un periodo de dos años, la disminución de la recesión gingival por medio de una técnica bilaminar mediante la utilización de un injerto subepitelial de tejido conectivo, ubicado debajo de un colgajo posicionado coronalmente, de espesor completo.

\section{MATERIALES Y MÉTODOS}

Población: Diez (10) pacientes sin compromiso sistémico, cinco (5) hombres y cinco (5) mujeres entre 18 y 45 años, con un promedio de 30 años de edad. Los pacientes presentaron 20 recesiones gingivales y necesitaban cubrimiento de ellas por motivos estéticos.

Los criterios de inclusión fueron: Pacientes sin compromiso sistémico, ninguna contraindicación para cirugía periodontal, no fumador, ninguna cirugía periodontal en las recesiones, objeto de estudio, en los 24 meses previos, presencia de recesiones gingivales, presencia de unión cemento-amélica identificable, vitalidad dental y ausencia de restauraciones en los dientes involucrados en la investigación.

Considerando el artículo 11 de la resolución 008430 de 1993 del Ministerio de Salud de Colombia, este trabajo se consideró como una investigación sin riesgo. Así, todos los pacientes firmaron el consentimiento informado para participar en el estudio clínico durante dos (2) años. A todos se les dio instrucción de higiene oral para eliminar los hábitos que pudieran causar recesión. Se practicaron cuatro (4) sesiones de debridamiento periodontal, y profilaxis para remover los depósitos microbianos de la superficie radicular. Se evaluó la habilidad de los pacientes para mantener una higiene oral adecuada.

Procedimiento quirúrgico: El cubrimiento radicular se realizó mediante una técnica bilaminar mediante la combinación de un injerto subepitelial, de tejido conectivo, combinado con un colgajo pediculado, de espesor total desplazado coronalmente, modificación de la técnica descrita por Langer y Langer. ${ }^{12}$ Todos los procedimientos quirúrgicos fueron realizados por el mismo cirujano.

Después de anestesiar infiltrativamente, la superficie radicular expuesta se alisó cuidadosamente con curetas. Se realizó un colgajo de espesor total con dos incisiones verticales, ubicadas por lo menos a la distancia correspondiente a la mitad de la amplitud mesiodistal del diente con recesión gingival. Se efectuó una incisión horizontal crevicular a nivel del margen gingival, con el fin de preservar el tejido gingival presente sobre la superficie radicular, dicha incisión se extendió hasta la base de las papilas, a las cuales se les eliminó el epitelio para facilitar la revascularización, una vez el colgajo desplazado coronalmente fuera reposicionado (Figuras 1 y 2). Se elevó un colgajo de espesor total, exponiendo la superficie ósea (Figura 2). 
Luego se obtuvo un injerto de tejido conectivo subepitelial del paladar periostizado. El área donante se limitó a un área comprendida entre el canino y el primer molar. Se realizaron dos incisiones paralelas, de 1 a $1.5 \mathrm{~mm}$, distantes por lo menos $5 \mathrm{~mm}$ del margen gingival de los dientes superiores y con una amplitud dependiente de la recesión a cubrir. Se practicaron también incisiones verticales para proporcionar un mayor acceso (Figuras 3, 4, 5). El injerto debería tener por lo menos un espesor de $1 \mathrm{~mm}$; se eliminó el tejido graso y se descartó el epitelio (Figura 6).

El tejido conectivo se suturó a periostio sobre el lecho, utilizando una sutura reabsorbible 5-0 que permitiera un íntimo contacto entre los tejidos (Figura 7). El área donante se suturó con seda 5/0 (Figura 8).

El colgajo de espesor total del área receptora fue posicionado y suturado coronalmente, evitando una tensión innecesaria del tejido (Figura 9). Se colocó cemento quirúrgico y se proporcionaron al paciente las medidas postquirúrgicas y de higiene oral pertinentes. El paciente fue evaluado a los 7 días para remover el apósito quirúrgico. Todos los pacientes fueron sometidos a enjuagues de clorhexidina al $0.12 \%$ durante dos semanas y se les realizó profilaxis semanal durante el primer mes, y posteriormente a intervalos mensuales.

Mediciones clínicas: Los registros de los datos iniciales fueron hechos inmediatamente antes del procedimiento quirúrgico y en los grupos de comparación: 1, 3, 6, 12, 18 y 24 meses postquirúrgicos. Previo al estudio se calibraron dos examinadores para reducir el error intra e inter examinador (Kappa > 0.75) para establecer confiabilidad y uniformidad. La inspección de la información fue realizada por el mismo examinador, en el mismo paciente, en todos los exámenes clínicos.

Para la evaluación de la higiene oral y salud gingival se emplearon un índice de placa (IP $)^{31} \mathrm{y}$ un índice gingival (IG)..$^{32} \mathrm{El}$ sondaje fue realizado utilizando una sonda periodontal estándar, con incrementos de $1 \mathrm{~mm}$. La recesión gingival (RG) fue medida entre el punto más apical de la unión cemento amélica vestibular y la posición más apical del margen gingival bucal. El nivel de inserción (NIC) se midió entre la unión cemento amélica y la base del surco. La amplitud de la encía queratinizada (AEQ) se determinó desde el punto más apical del margen gingival hasta la unión mucogingival. Todas las medidas se realizaron en todos los sitios experimentales.

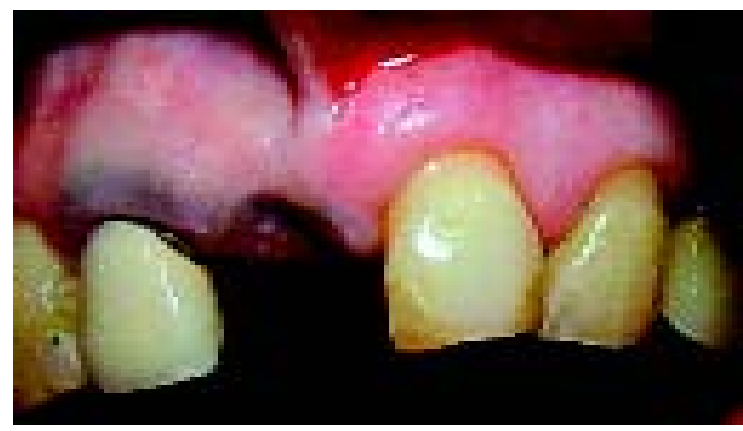

Figura 1. Recesión gingival Clase I de Miller en 21 y 22.

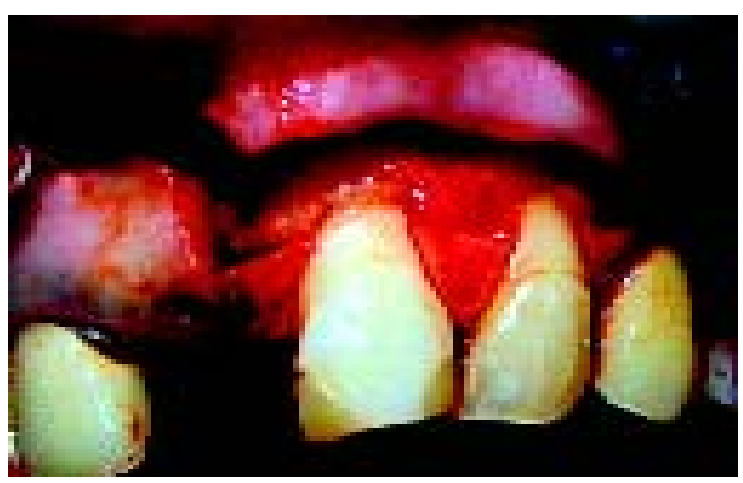

Figura 2. Elevación de colgajo de espesor parcial.
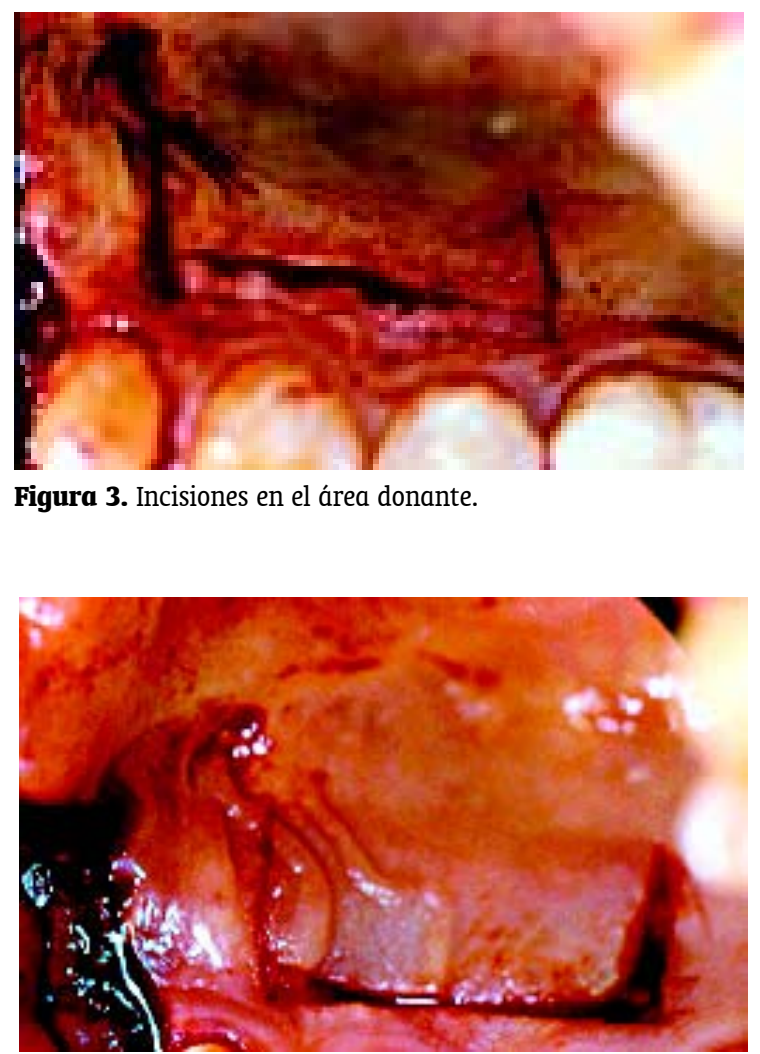

Figura 4. Elevación colgajo dividido en paladar. 


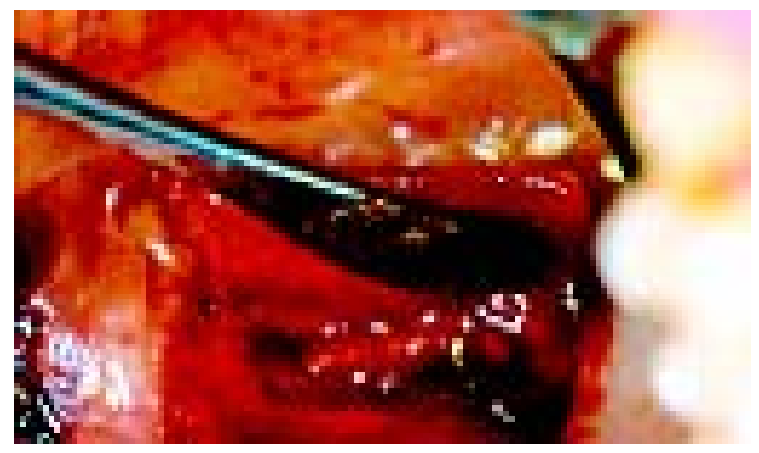

Figura 5. Elevación colgajo dividido en paladar.

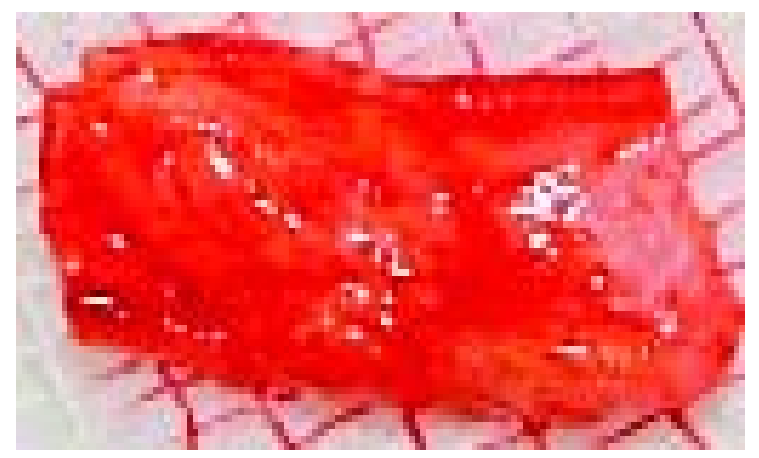

Figura 6. Injerto de tejido conectivo.

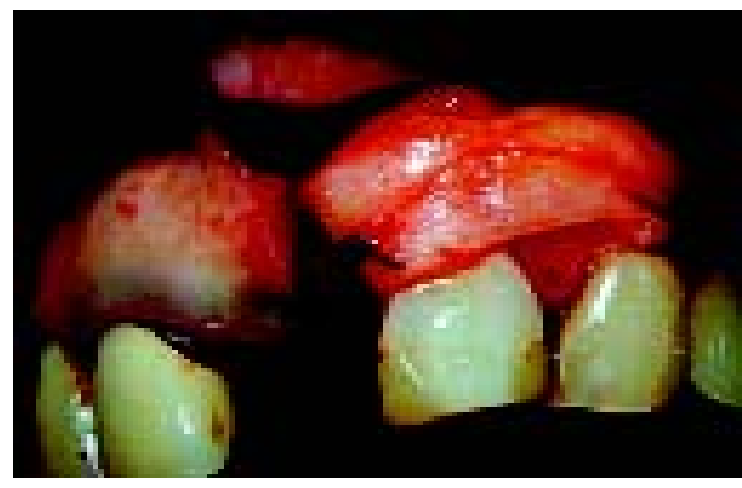

Figura 7. Injerto suturado en el área de la recesión.

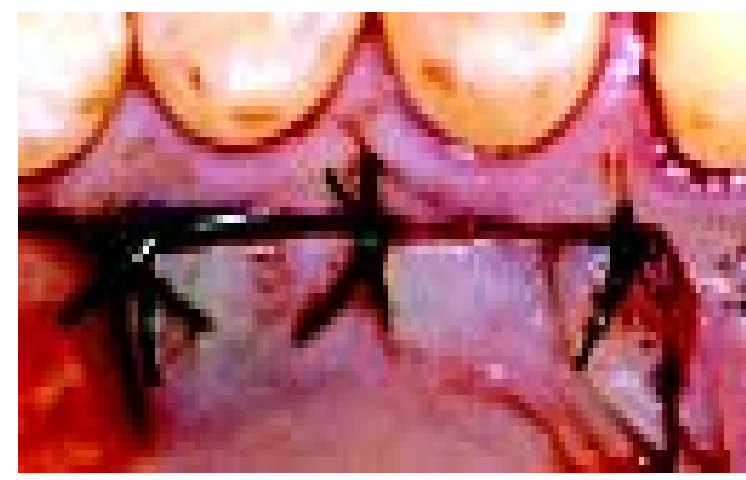

Figura 8. Suturas en el paladar.

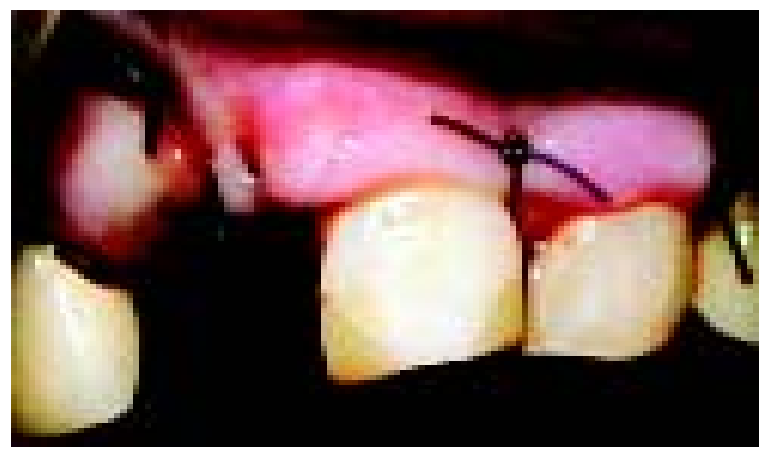

Figura 9. Colgajo desplazado coronalmente cubriendo el injerto de tejido conectivo.

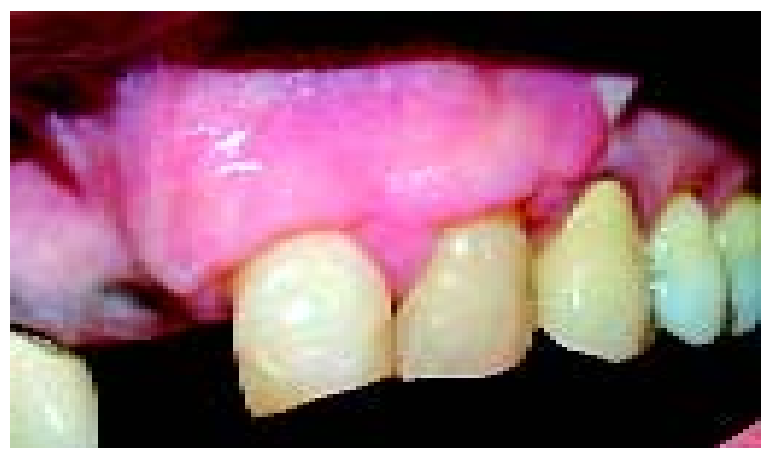

Figura 10. Posoperatorio, seis meses después.

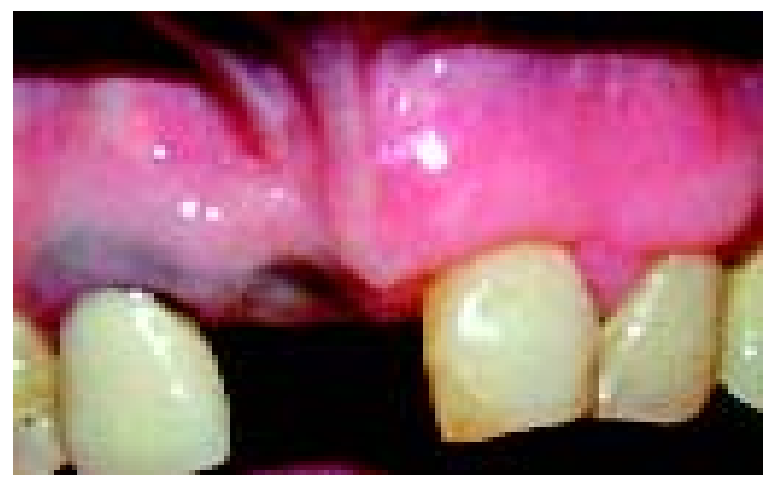

Figura 11. Postoperatorio 24 meses.

Análisis estadístico: La estadística descriptiva fue expresada con promedios más la desviación estándar (DS). El porcentaje de cubrimiento radicular fue calculado como $\left(R G_{\text {prequirúrgica }}-R G_{24 \text { meses }}\right) / R G_{\text {prequirúrgica }}$. La revisión postoperatoria correspondiente al primer mes fue seleccionada como el punto de inicio de inserción trepadora. ${ }^{21}$ La inserción trepadora, a partir del primer mes, se calculó como $R G_{1 \text { mes }}-R G_{\text {cada período }}$. Las variaciones longitudinales fueron evaluadas por medio de análisis de varianza ( $\mathrm{RG}$, inserción trepadora NIC y $\mathrm{AEQ}$ ) o test de Friedman (IP e IG). Se aceptó una probabilidad de $\mathrm{P}<$ 0.05 para rechazar la hipótesis nula. 


\section{RESULTADOS}

La tabla 1 muestra la distribución y clasificación de Miller $^{33}$ de los 20 sitios de recesión gingival; 10 bicúspides, 5 caninos y 5 incisivos representaban 15 recesiones Clase I y 5 recesiones clase II. Los resultados de un caso representativo son ilustrados en las figuras 10 y 11.

Los pacientes mostraron óptimos niveles de higiene oral a través de un período de observación (Tabla 2). El promedio de IP varió entre 0.1 y 0.2 y el de IG entre 0.3 y 0.4 .

La Tabla 3 presenta los cambios de altura gingival observados durante el período de evaluación. La recesión gingival disminuyó de $3.4 \pm 0.58$ como punto de inicio a $0.31 \pm 0.43$ en 24 meses, representando una reducción de 3.16 correspondiendo al $91.2 \% \pm 8.47$ de cubrimiento radicular en promedio. En la evaluación final, a los 24 meses, 14 de los 20 (70\%) sitios mostraban un cubrimiento radicular del $100 \%$. El promedio de RG se redujo a 0.85 en un (1) mes postoperatorio y posteriormente se disminuyó a 0.28 en doce (12) meses. Después de los doce (12) meses, $R G$ permaneció estable. En las figuras 10 y 11 se observa la disminución de una recesión y su estabilidad hasta los primeros dos (2) años. Durante los 3, 6, 12, 18 y 24 meses los valores promedios de $R G$ fueron significativamente menores, comparados con el primer mes. 4 de los 20 sitios mostraron completo cubrimiento en el primer mes, posterior a la cirugía; 8 sitios, a los 3 meses; 10 sitios, a los 6 meses; 13 sitios, a los doce meses; y 14 sitios, a los 24 meses. Se cree que el fenómeno de inserción trepadora es el responsable de este cambio en el nivel gingival.

La mayor cantidad de inserción trepadora (0.58\%) se observó a los doce meses. La ganancia en el nivel de inserción clínica está representada en la Tabla 4. Se observa una disminución en el NIC desde el punto de inicio (5.06 \pm 0.71 ) comparado con los resultados a los 24 meses (2.1 \pm 0.58 ). En el primer mes posterior a la cirugía, el NIC fue de $2.7 \pm 0.7$. El patrón de comportamiento fue similar para RG. Se observó ganancia de inserción clínica desde el primero hasta el décimosegundo mes postoperatorio, después del cual permaneció estable hasta el segundo año de observación (3.17). El promedio de encía queratinizada (Tabla 5) aumentó en 24 meses a $1.98 \mathrm{~mm}$. La AEQ incrementó desde $0.8 \pm 0.7$, en el punto de inicio, hasta $2.8 \pm 0.4$ en un mes, después del cual permaneció estable.

\begin{tabular}{llccc}
\hline & \multicolumn{2}{c}{ MAXIL.AR } & \multicolumn{2}{c}{ MANDIBUL.AR } \\
\hline & \multicolumn{3}{c}{ C.ASIFICACIÓN DE MIL.ER } \\
\hline DIENTE & I & II & I & II \\
Incisivos & 2 & 0 & 2 & 1 \\
Caninos & 2 & 1 & 2 & 0 \\
Bicúspides & 3 & 3 & 4 & 0 \\
TOTAL. & 7 & 4 & 8 & 1 \\
\hline
\end{tabular}

Tabla 1. Distribución de las recesiones

\begin{tabular}{lccccccc}
\hline \multicolumn{7}{c}{ MES } \\
\hline & INICIO & $\mathbf{1}$ & $\mathbf{3}$ & $\mathbf{6}$ & $\mathbf{1 2}$ & $\mathbf{1 8}$ & 24 \\
IP $(\mathbf{0}-3)$ & $0.2 \pm 0.2$ & $0.1 \pm 0.2$ & $0.2 \pm 0.2$ & $0.1 \pm 0.2$ & $0.2 \pm 0.2$ & $0.1 \pm 0.2$ & $0.2 \pm 0.2$ \\
IG $(\mathbf{0}-3)$ & $0.3 \pm 0.4$ & $0.3 \pm 0.3$ & $0.3 \pm 0.3$ & $0.3 \pm 0.4$ & $0.3 \pm 0.4$ & $0.3 \pm 0.3$ & $0.3 \pm 0.3$ \\
\hline
\end{tabular}

Tabla 2. Resultados del indice de placa (IP) e indice gingival (IG) previo y posterior a la cirugia. Ningún periodo mostró diferencias estadisticamente significativas (Test Friedman)

\begin{tabular}{|c|c|c|c|c|c|c|c|}
\hline & \multicolumn{5}{|c|}{ MES } & \multirow[b]{2}{*}{18} & \multirow[b]{2}{*}{24} \\
\hline & INTCIO & 1 & 3 & 6 & 12 & & \\
\hline RG (mm) & $3.4 \pm .58$ & $.85 \div .41^{*}$ &, $53 \pm, 43^{*}+$ & $.33 \pm .32^{*}+$ & $.28 \pm .36^{\circ}+$ & $28 \pm 36^{\circ}+$ & $31 \pm-43^{*}+$ \\
\hline Disminución RG & & $2.71 \pm .41$ & $3.02 \pm .52$ & $3.12 \pm .43$ & $3.13 \pm .53$ & $3.15 \pm .52$ & $3.16 \pm 52$ \\
\hline Cubrimiento radicular (9) & & $75.0 \pm 9.9$ & $85.1 \pm 9.8$ & $90.5 \pm 9.9$ & $91.0 \pm 9.7$ & $912 \pm 9.5$ & $91.6 \pm 8.47$ \\
\hline $\begin{array}{l}\text { No, de sitios completamente } \\
\text { cubiertos }\end{array}$ & & 4 & 8 & 10 & 13 & 13 & 14 \\
\hline Inserción trepadora & & & $3 \pm .29$ & $.51 \pm .3418$ & $.58 \pm 318$ & $58 \pm 318$ & $58 \pm 318$ \\
\hline
\end{tabular}

Tabla 3. Cambios en la altura gingival antes y después de la cirugia.

* $\mathrm{p}<001$ : significativamente diferente del inicio (ANOVA).

$+\mathrm{p}<001$ : significativamente diferente de 1 mes.

1 p $<0.05$ : significativamente diferente de 3 meses.

$\&$ p > 0.05: no hay diferencia significativa entre los valores $6,12,18$ y 24 meses. 


\begin{tabular}{lccccccc}
\hline \multicolumn{7}{c}{ MES } \\
\hline NIC (mm) & INICIO & 1 & 3 & 6 & 12 & 18 & 24 \\
Ganancia inserción & $5.06 \pm 0.71$ & $2.4 \pm .5^{*}$ & $2.3 \pm .4^{*}$ & $2.1 \pm 3^{*}$ & $2.0 \pm .5^{*}$ & $2.0 \pm 5^{*}$ & $2.1 \pm .58^{*}$ \\
& & $2.7 \pm .7$ & $2.9 \pm .5$ & $3.1 \pm .5$ & $3.1 \pm .5$ & $3.15 \pm .5$ & $3.17 \pm .4$ \\
\hline
\end{tabular}

Tabla 4. Nivel de inserción clinica (NIC) antes y después de la cirugia.

${ }^{*} \mathrm{p}<0.01$ : significativamente diferente desde el inicio (ANOVA)

\begin{tabular}{lccccccc}
\hline \multicolumn{7}{c}{ MES } \\
\hline & INICIO & 1 & 3 & 6 & 12 & 18 & 24 \\
AEQ (mm) & $.8 \pm .7$ & $2.71 \pm 4^{*}$ & $2.72 \pm .5^{*}$ & $2.73 \pm 4^{*}$ & $2.79 \pm .3^{*}$ & $2.79 \pm 3^{*}$ & $2.8 \pm .^{*}$ \\
Incremento AEQ & & $1.91 \pm .5$ & $193 \pm .4$ & $1.94 \pm .3$ & $1.98 \pm 3$ & $1.98 \pm .3$ & $1.98 \pm .6$ \\
\hline
\end{tabular}

Tabla 5. Amplitud de encia queratinizada antes y después de la cirugia

${ }^{*} \mathrm{p}<0.01$; significativamente diferente del inicio (ANOVA)

\section{DISCUSIÓN}

Los resultados de este estudio confirman la predecibilidad de esta Técnica Bilaminar, empleando un injerto de tejido conectivo colocado bajo un colgajo pediculado, desplazado coronalmente, de espesor total, como una técnica efectiva para obtener un cubrimiento estético de una recesión gingival.

El cubrimiento radicular promedio, desde el punto de inicio hasta el segundo año de evaluación, fue del 91.2\% para este grupo constituido por 20 recesiones en 10 pacientes. Un completo cubrimiento radicular se obtuvo en 14 sitios (70\%). El promedio en ganancia de inserción se compara con los resultados obtenidos en otros estudios empleando técnicas diferentes. Raetzke ${ }^{11}$ obtuvo $100 \%$ de cubrimiento radicular, en $41.7 \%$ de los casos y $80 \%$ en promedio de cubrimiento radicular, a los ocho meses postquirúrgicos empleando la técnica; Jahnke y colaboradores $^{9}$ reportaron $80 \%$ en promedio de cubrimiento radicular después de 6 meses usando injertos de tejido conectivo. Müller y colaboradores ${ }^{22}$ obtuvieron $73 \%$ en promedio de cubrimiento radicular a los doce meses utilizando la técnica en sobre; Nelson ${ }^{13}$ obtuvo $100 \%$ de cubrimiento radicular en $62 \%$ de los casos y $91 \%$ de cubrimiento radicular promedio empleando una técnica bilaminar en un estudio durante 42 meses. Borghetti y Louise ${ }^{14}$ reportaron $70.9 \%$ de cubrimiento radicular promedio utilizando una técnica de colgajo pediculado de espesor total en una investigación de 12 meses. Harris ${ }^{1921,23}$ obtuvo un alto porcentaje de cubrimiento radicular comparado con otros autores, reportando $97.4 \%$ en 12 semanas, ${ }^{19} 97.7 \%$ en un promedio de 23 semanas, ${ }^{20}$ y $97.1 \%$ a 26 semanas ${ }^{23}$ usando un injerto pediculado doble de espesor parcial. Excepto por el estudio realizado por Nelson, ${ }^{13}$ la mayoría de investigaciones reportaron estudios mayores a un año de evaluación. Paolantonio y colaboradores ${ }^{10}$ presentaron resultados de un estudio clínico, durante 5 años, con un $85.23 \%$ de cubrimiento radicular y $2.81 \mathrm{~mm}$ de aumento en la encía queratinizada, en comparación con los resultados de este estudio.

RG, NIC y AEQ tuvieron resultados más positivos en 12 meses. RG y NIC disminuyeron significativamente, en el primer mes, comparados con los datos prequirúrgicos; posteriormente se redujeron hasta los doce meses.

La AEQ aumentó significativamente después de un mes de realizado el procedimiento quirúrgico y permaneció estable por 24 meses.

La inserción trepadora fue descrita primero por Goldman y colaboradores ${ }^{34}$ como "la migración positiva del margen gingival en dirección coronal sobre una raíz previamente denudada". Esta migración es a menudo vista, después de periodos postoperatorios, hasta que alcanza un nivel marginal constante. Mientras la cantidad de inserción trepadora es mínima (menor a $1 \mathrm{~mm}$ ) su importancia clínica puede ser significativa, pues mejora la predicibilidad de un procedimiento. Harris ${ }^{21}$ reportó que la inserción trepadora parece ocurrir comúnmente después de injertos de tejido conectivo. Basado en hallazgos previos, Harris seleccionó la cuarta semana postoperatoria como el punto de inicio de este fenómeno. En su estudio, 21 de 22 casos (95.5\%) mostraron inserción trepadora y el promedio de inserción obtenida fue de 0.8 
milimetros en un período de 8 semanas. En el presente estudio se observó $1 \mathrm{~mm}$ de inserción trepadora en 24 meses después de la cirugía y ocurrió en 14 de los 20 sitios (70\%). La recomendación de que un año es el período ideal para la evaluación, se basa en estudios sobre injerto gingival libre. ${ }^{6,7}$ En la presente investigación, la inserción trepadora es mayor a doce meses de realizada la cirugía.

En este estudio no se empleó ningún agente acondicionador de la superficie radicular durante la cirugía. Muchos investigadores han empleado ácido cítrico $0^{9,15,16}$ o tetraciclina ${ }^{16,19-24}$ en la biomodificación de la superficie radicular, basados en la creencia de que al remover el smear layer y exponer las fibras de colágeno se mejoraría la reinserción del injerto. Sin embargo Bouchard y colaboradores ${ }^{15}$ fracasaron en demostrar el beneficio del ácido cítrico como acondicionante de la superficie radicular, cuando se emplearon injertos subepiteliales de tejido conectivo. En otro reporte, Ios investigadores fracasaron en demostrar diferencias entre la tetraciclina y el ácido cítrico, aplicados sobre superficies radiculares. ${ }^{16}$

El objetivo ideal en una terapia periodontal es la regeneración tisular, por una nueva inserción de tejido conectivo, con fibras insertadas en el nuevo hueso y en el nuevo cemento. Estudios histológicos en animales $^{35} \mathrm{y}$ en humanos ${ }^{36}$ revelan que no se ha observado verdadera regeneración sobre superficies radiculares cubiertas con injertos de tejido conectivo, y que las biopsias realizadas indican que la inserción de los injertos es mediada por una combinación de crecimiento epitelial e inserción de tejido conectivo, con poco potencial para la formación de nuevo hueso y nuevo cemento. Sin embargo, a pesar de los hallazgos histológicos, los injertos de tejido conectivo son un método eficaz para lograr el cubrimiento radicular. Los resultados obtenidos son adecuados y parecen estables en un periodo de dos (2) años, como se demuestra en el presente estudio.

En conclusión, la Técnica Bilaminar empleando un injerto de tejido conectivo combinado con un colgajo pediculado de espesor total desplazado coronalmente, es un método predecible para cubrir raíces, y la utilidad obtenida por esta técnica puede ser bien sustentada.

\section{BIBLIOGRAFÍA}

1. Goldstein M, Brayer L, Schwartz Z. A critical evaluation of methods for root coverage. Crit Rev Oral Biol 1996; 7: 87 - 89.

2. Caffesse RG, Alspach SR, Morrison EC, Burgett FG. Lateral sliding flaps with and without citric acid. Int J Periodontics Restorative Dent 1987; 7: 43 - 57.

3. Allen EP, Miller PD. Coronal positioning of existing shallow marginal tissue recession. J Periodontol 1989; 60: 316 - 319.

4. Romanos G, Bernimoulin JP, Marggraf E. The double lateral bridging flap for coverage of denuded root surface: Longitudinal study and clinical evaluation after 5 to 8 years. J Periodontol 1993; 64: 683 - 688 .

5. Trombelli L, Scabbia A, Wikesjo UM, Calura G. Fibringlue application in conjunction with tetracycline root conditioning and coronally positioned flap in the treatment of human gingival recession defects. J Clin Periodontol 1996; 23: 861 - 867.

6. Borghetti A, Gardella JP. Thick gingival autograft for the coverage of gingival recession: A clinical evaluation. Int J Periodont Rest Dent 1990; 10: 217 - 229.

7. Matter J. Creeping attachment of free gingival grafts: A five year follow-up study. J Periodontol 1980; 51: 681 - 685.

8. Laney JB, Saunders VA, Garnick JJ. A comparison of two techniques for attaining root coverage. J Periodontol 1992; 63: 19 - 23.

9. Jahnke PV, Sandifer JB, Gher ME, Gray JL, Richardson AC. Thick free gingival and connective tissue autografts for root coverage. J PeriodontoI 1993; 64: 315 - 322.

10. Paolantonio M, di Murro C, Cattabriga A, Cattabriga M. Subpedicle connective tissue graft versus free gingival graft in the coverage of exposed root surfaces. A 5-year clinical study. J Clin PeriodontoI 1997; 24: 51 - 56.

11. Raetzke PS. Covering localized areas of root exposure employing the “envelope" technique. J Periodontol 1985; 56: 397 - 402.

12. Langer S, Langer L. Subepithelial connective tissue graft technique for root coverage. J Periodontol 1985; 56: 715 - 720.

13. Nelson SW. The subpedicle connective tissue graft. A bilaminar reconstructive procedure for coverage of denuded root surfaces. J PeriodontoI 1987; 58: 95 -102.

14. Borghetti A, Louise F. Controlled clinical evaluation of the subpedicle connective tissue graft for the coverage of gingival recession. J PeriodontoI 1994; 65: 1107 - 1112.

15. Bouchard P, Etienne D, Ouhayoun JP, Nilveus R. Subepithelial connective tissue grafts in the treatment of gingival recessions. A comparative study of 2 procedures. J PeriodontoI 1994; 65: 929 - 936. 
16. Bouchard P, Nilveus R, Etienne D. Clinical evaluation of tetracycline $\mathrm{HCI}$ conditioning in the treatment of gingival recession. A comparative study. J Periodontol 1997; 68: 262 269.

17. Allen AL. Use of the supraperiosteal envelope in soft tissue grafting for root coverage: Rationale and technique. Int J Periodontics Restorative Dent 1994; 14: 216 - 227.

18. Allen AL. Use of the supraperiosteal envelope in soft tissue grafting for root coverage: Clinical results. Int J Periodontics Restorative Dent 1994; 14: 302-315.

19. Harris RJ. The connective tissue and partial thickness double pedicle graft: A predictable method of obtaining root coverage. J Periodontol 1992; 63: 477 -486.

20. Harris RJ. The connective tissue with partial thickness double pedicle graft: The results of 100 consecutively treated defects. J Periodontol 1994; 65: 448 - 461.

21. Harris RJ. Creeping attachment associated with the connective tissue graft with partial-thickness double pedicle graft. J PeriodontoI 1997; 68: 890 - 899.

22. Müller HP, Eger T, Schorb A. Gingival dimensions after root coverage with free connective tissue grafts. J Clin PeriodontoI 1998; 25: 424 - 430.

23. Harris RJ. A comparative study of root coverage obtained with guided tissue regeneration utilizing a bioabsorbable membrane versus the connective tissue with partial-thickness double pedicle graft. J Periodontol 1997; 68: 779 - 790.

24. Jepsen K, Heinz B, Halben J, Jepsen S. Treatment of gingival recession with titanium reinforced membranes versus connective tissue grafts. J Periodontol 1998; 69: 383 - 391.

25. Tinti C, Vincenzi G, Cortellini P, Pini Prato G, Clauser C. Guided tissue regeneration in the treatment of human facial recession. A 12-case report J Periodontol 1992; 63: $554-560$.

26. Roccuzzo M, Lungo M, Corrente G, Gartdolfo S. Comparative study of a bioresorbable and a non-resorbable membrane in the treatment of human buccal gingival recessions. J Periodontol 1996; 67: 7 - 14

27. Rachlin G, Koubi G, Dejou J, Franquin JC. The use of a resorbable membrane in mucogingival surgery. Case series. J Periodontol 1996; 67: 621 - 626.

28. Shieh AT, Wang HL, O'Neal R, Glickman GN, MacNeil RL. Development and clinical evaluation of a root coverage procedure using a collagen barrier membrane. J PeriodontoI 1997; 68: 770 - 778.

29. Hancock EB. Regeneration procedures In: Proceedings of the World Workshop in Periodontics. Chicago: The American Academy of Periodontology, 1989; VII -1- VII - 21.
30. de Waal H, Kon S, Ruben MP. The laterally positioned flap. Dent Clin North Am 1988; 32: 267 - 285.

31. Silness J, Loe H. Periodontal disease in pregnancy. Correlation between oral hygiene and periodontal condition. Acta Odontol Scand 1964; 21: 121 - 135.

32. Loe $\mathrm{H}$, Silness J. Periodontal disease in pregnancy. Prevalence and severity. Acta Odontol Scand 1963; 22: 533 - 551.

33. Milier PD. A classification of marginal tissue recession. Int $\mathrm{J}$ Periodontics Restorative Dent 1985; 5: 8 - 13.

34. Goldman H, Schluger S, Fox L, Echen DW. Periodontal Therapy, 3rd ed. Sto Louis: C.V. Mosby Co.; 1964: 560.

35. Guiha R, Khodeiry SE, Mota L, Caffesse R. Histological evaluation and healing and revascularization of the subepithelial connective tissue graft. J Periodontol 2001; 72: 470 - 478.

36. Harris RJ. Human histologic evaluation of root coverage obtained with a connective tissue with partial thickness double pedicle graft. A case reporto J Periodontol 1999; 70: 813 - 821. 